Revista Mídia e Cotidiano

Artigo Seção Temática

Volume 11, Número 3, dezembro de 2017

Submetido em: 05/10/2017

Aprovado em: 28/11/2017

\title{
A CIRCULACCÃO DE REPRESENTAÇÕES SOCIAIS DE FAVELAS DO RIO DE JANEIRO NO DISCURSO FOTOJORNALÍSTICO
}

\section{THE CIRCULATION OF SOCIAL REPRESENTATIONS OF THE SHANTYTOWNS OF RIO DE JANEIRO THROUGH THE PHOTOJOURNALISTIC DISCOURSE}

\author{
Janaina BARCELOS ${ }^{1}$
}

\section{Resumo:}

O surgimento e desenvolvimento das favelas no Rio de Janeiro foram acompanhados da circulação de discursos sobre esses locais e seus moradores. Tais discursos colaboraram para construção e manutenção de representações sociais cristalizadas, que categorizam as favelas e reduzem sua diversidade, engendrando imaginários majoritariamente ligados à marginalidade e à violência. Em contrapartida, há discursos que buscam combater essa visão hegemônica e redutora e revelar essa complexidade, em vez de estigmatizar. Este estudo traz o resultado de análises de fotos jornalísticas sobre favelas cariocas publicadas no jornal "O Globo" e no livro "Imagens do Povo". Procuramos verificar, via a análise do discurso, quais representações sociais as fotos mobilizam e quais imaginários elas produzem, vinculados a quais sentidos.

Palavras-chave: Discurso; Favelas do Rio de Janeiro; Fotojornalismo; Representação Social.

\begin{abstract}
:
The emergence and development of shantytowns in Rio de Janeiro were followed by the circulation of discourses about these places and its inhabitants. Such discourses contribute to the construction and maintenance of crystallized social representations that categorize the shantytowns and reduce their diversity, engendering imaginaries that are mostly linked to their marginalization and violence. By contrast, there are discourses aiming to fight against this hegemonic and reductive impression. They reveal this complexity instead of stigmatize it. This study shows the results of an analysis of journalistic photographs about the shantytowns in Rio de Janeiro that were published on the newspaper "O Globo", and on the book "Imagens do Povo" (Images of the People). Through discourse analysis we tried to verify which social representations were mobilized by the images, which imaginaries they create and to which senses they are connected.
\end{abstract}

Keywords: Discourse; Shantytowns of Rio de Janeiro; Photojournalism; Social Representation.

\footnotetext{
${ }^{1}$ Doutora em Estudos Linguísticos - Análise do Discurso (UFMG), mestre em Comunicação e Jornalismo (Universidade de Coimbra), jornalista graduada pela UFMG, professora da UFSJ / janabarcelos@hotmail.com
} 


\section{míiA

Introdução

Desde o seu surgimento no Rio de Janeiro nos idos do século XIX, as favelas foram sendo retratadas a partir de determinadas representações sociais, as quais colaboraram para a construção de um imaginário sobre o lugar e seus moradores. Os discursos que circularam de lá para cá apontam para representações cristalizadas - ou estereótipos -, que acabam por simplificar a imagem que se tem desses espaços urbanos e categorizar os seus habitantes de modo generalizante. Histórica, social, cultural e discursivamente, as favelas cariocas carregaram e ainda carregam representações ligadas, principalmente, à criminalidade, conduzindo a imaginários de violência, medo e divisão asfalto/morro. Em contrapartida, surgem também discursos contra-hegemônicos que buscam apresentar tais locais e seus habitantes em sua diversidade, a fim de combater estigmas e construir sentidos que apontem para uma visão mais multifacetada e condizente com o modo como essas populações se veem.

Este trabalho pretende refletir sobre os processos de construção de sentidos pelo jornalismo, a partir da análise do discurso de fotos jornalísticas/documentais, para verificar qual a imagem da favela carioca e de seus moradores vem sendo engendrada. Trata-se de uma compilação de parte da nossa tese de doutorado "Imagem e produção de sentido sobre favelas cariocas em fotos jornalísticas", acrescida de novas análises, que incluem fotos do livro "Imagens do Povo". Para este artigo, na abordagem teórica, damos ênfase aos aspectos que contemplam os conceitos de representação social, estereótipos e imaginários sociodiscursivos, evidenciando como o discurso fotojornalístico atua na elaboração de sentidos possíveis.

Partimos dos resultados obtidos na tese, que verificou cerca de 300 fotos de favelas cariocas publicadas no jornal "O Globo" durante os meses de setembro, outubro e novembro dos anos 2010, 2012 e 2014, em contraposição à proposta do programa Imagens do Povo, a partir das fotos reunidas no livro de mesmo nome, publicado em 2012. Esclarecemos que a análise das fotografias dessa obra é um trabalho que se encontra em andamento, mas que já apresenta resultados preliminares que permitem essa confrontação de diferentes propostas discursivas. 
O universo das favelas do Rio de Janeiro: algumas percepções

Vários autores se debruçaram em estudos para compreender o processo de surgimento e desenvolvimento das favelas no Rio de Janeiro. Entre os principais pesquisadores, citamos Valladares $(2000,2005)$, que trabalha com o tema há mais de quarenta anos, sendo referência na área de Ciências Sociais. A autora também discute como vários discursos que circularam no final do século XIX e início do XX colaboraram para a formação de representações sobre as favelas, que se originaram das construções de diferentes atores sociais.

\begin{abstract}
Seus estudos mostram que a gênese do processo de construção das representações sociais das favelas remonta às descrições e imagens que nos foram legadas por escritores, jornalistas e reformadores sociais do início do século XX. Amplamente divulgados naquela época, esses textos permitiram o desenvolvimento de um imaginário coletivo sobre as favelas e seus moradores, ao mesmo tempo em que opunham favela e cidade. Tais discursos circulantes dos quais a autora fala, apesar de originários de diferentes tendências ideológicas e políticas, carregavam percepções semelhantes, que são discutidas por ela ao longo da obra. (BARCELOS, 2016, p. 63-64)
\end{abstract}

Campos (2007) e Silva \& Barbosa (2005) dialogam com as discussões de Valladares (2000, 2005) e também apontam outras abordagens, que auxiliaram a compreender esse caminho de construção de determinadas visões sobre as favelas e seus moradores. Parte do modo de olhar para esses espaços e pessoas passa, ainda, por políticas públicas que privilegiam remoções, por uma concepção higienista, civilizatória e estética e por um modelo europeu de cidade, enfim por aspectos que enquadram as favelas como problema.

Apenas no final dos anos 1930, as favelas foram reconhecidas oficialmente como um tipo de espaço urbano presente no território do então Distrito Federal, por meio do Código de Obras do Rio de Janeiro. No entanto, o documento se refere a elas como habitações anti-higiênicas, portanto, como objeto de intervenção. A partir dos anos 1940, as primeiras comunidades começam a se mobilizar contra remoções e em busca de articulações comunitárias e do enfrentamento de representações sociais cristalizadas (SILVA \& BARBOSA, 2005). Na década de 1970, entram em cena discursos que enquadram a favela como espaço forte em família, associação e vizinhança, conforme estudos de Zaluar \& Alvito (1999), porém tal visão acaba sobrepujada por aquela que a 
categoriza como local de criminalidade, devido ao fortalecimento do tráfico de drogas a partir dos anos 1980 .

De modo geral, as representações das favelas se solidificaram em torno do imaginário da ausência e da carência, de acordo com Silva \& Barbosa (2005, p. 57), fundadas em "pré-conceitos e juízos generalizantes", pois são desprezadas e ignoradas as estratégias criativas, complexas e heterogêneas dos moradores para melhorar sua qualidade de vida, e desconsideradas suas vivências, redes de sociabilidade e participação na vida pública.

No movimento para que essa visão complexa e diversa das favelas tenha lugar no espaço público, encontram-se algumas organizações, como o Observatório de Favelas, a Central Única das Favelas e o Viva Favela, bem como associações comunitárias, que buscam formas de mobilização, informação e combate à desigualdade. O Observatório, por exemplo, procura refutar pressupostos sustentados pelos imaginários de carência e homogeneidade, por acreditar que eles se definem a partir do que as favelas não são em comparação a um ideal do urbano, em vez de encará-las como moradas singulares no conjunto da cidade, que compõem e integram o tecido urbano ${ }^{2}$.

A construção da imagem das favelas cariocas passa ainda por manifestações artístico-culturais, como artes plásticas, música, carnaval. Silva \& Barbosa (2005, p. 34) comentam como movimentos culturais promoveram uma espécie de "exotização da favela", elegendo-a como símbolo da cultura nacional e berço do samba, espaço autêntico da vida carioca, sustentado por representações da beleza rústica, de palco de musas e poetas, da mulata e do malandro, modelos que também categorizam e simplificam. Com outro enfoque, surgem, nos anos 1990, manifestações como o hip hop e o funk, que procuram significar suas próprias experiências por meio da linguagem, em que a favela deixa de ser espaço genérico de barbárie - em um momento em que o tráfico de drogas já havia se consolidado - para se transformar em território com nome próprio, heterogêneo, local de moradia, com as práticas que a constituem, integrante da cidade (LOPES, 2009).

\footnotetext{
${ }^{2}$ Cf. Observatório de Favelas, 2009, p. 21.
} 
Em relação à produção televisiva no Brasil, Faustini $(2015)^{3}$ destaca a relevância de incluir o universo da periferia na grade de programação, de modo a contribuir para dar visibilidade a esses espaços e pessoas, entretanto aponta que a abordagem ainda é limitadora na forma de apresentar essa realidade, que tende para o melodrama e a lógica da malandragem, além de apresentar com superficialidade temas centrais como desigualdade e violação de direitos. Para ele, a periferia é reduzida a representações sociais de lugar festivo ou perigoso.

Encontramos estudos sobre a imagem da favela em vários campos disciplinares, e grande parte deles aponta para a permanência de representações sociais cristalizadas, ligadas a imaginários de violência, cidade partida, pobreza e marginalidade, ancoradas em esquemas homogeneizadores. E a imprensa tem sua parcela de responsabilidade na construção e circulação desses discursos:

\begin{abstract}
o trabalho de Baiense (2014) nos mostra quais foram as transformações ocorridas no discurso jornalístico sobre as favelas cariocas a partir dos anos 1980, em O Globo e Jornal do Brasil, até a década de 2000. Ela demonstra que, até meados dos anos 1990, a favela era enquadrada como lugar de ausência, e os favelados percebidos como vítimas da sociedade. Essa visão se modifica, no entanto, após o crescimento da criminalidade e do tráfico de drogas, quando a cobertura jornalística se torna mais espetacular, e as favelas passam a ser vistas como áreas de risco. Logo, a representação das favelas se desloca de lugar de carência para lugar do crime. Para a autora, essa visão das favelas como lugar de violência decorre de uma série de fatores, como a territorialização do local pelos traficantes, o aumento da criminalidade nos centros urbanos e a descrença nos políticos, porém ela ressalta que a mídia tem papel preponderante na reprodução e na fixação dessa visão no imaginário coletivo. (BARCELOS, 2016, p. 105)
\end{abstract}

Com a atual política de pacificação, a mídia passa a dar ênfase ao caráter pacífico das operações policiais, situando o Estado como agente libertador que incorpora as favelas à cidade. Assim, o enquadramento pelo viés da criminalidade permanece. $\mathrm{O}$ estudo de Rocha (2010) sobre o discurso da imprensa carioca assinala na mesma direção.

\footnotetext{
${ }^{3}$ Marcus Faustini é escritor, diretor de teatro e documentarista, nascido e criado na zona oeste do Rio. É autor do "Guia Afetivo da Periferia" (2009) e coautor de "O novo carioca" (2012). Em 2011, criou a metodologia da Agência de Redes para Juventude, que busca transformar ideias de jovens das favelas cariocas em projetos para impactar suas comunidades, aumentando suas redes e repertórios. A Agência recebeu, em 2012, o prêmio Calouste Gulbemkain, em Londres.

${ }^{4}$ Cf.: BAISENSE, Carla. O lugar da favela no noticiário carioca. Uma análise do enquadramento em O Globo e JB. Revista Ecopós, v. 17, n. 1, p. 1-19, 2014.
} 
A análise de Matheus \& Silva (2013) também identificou a figura do Estado como libertador do tráfico, posicionando o morador da favela como vítima, na cobertura jornalística. Já o artigo de Freitas et al. (2010), sobre o discurso da mídia envolvendo UPPs, megaeventos e segurança pública, reforça a mudança de enfoque que os veículos de comunicação têm adotado na construção de um imaginário de paz e felicidade.

Enfim, percebemos que as representações sociais das favelas como lugar de pobreza, perigo, desorganização, precariedade parecem ter se cristalizado ao longo do tempo, apesar de estudos e tentativas de apresentar tal espaço urbano como heterogêneo, com sua diversidade.

\section{As noções que nos conduzem: representações sociais ou estereótipos}

Para entender esse universo de significações possíveis e como poderíamos operacionalizá-las na análise, partimos do conceito de representações sociais presente em Moscovici (2011), pois ele serviu de base para outra noção com a qual trabalhamos: a de imaginários sociodiscursivos, proposta por Charaudeau (2007) para integrar o campo de estudos da Análise do Discurso. Assim, trata-se de imaginários que são engendrados pelas representações sociais nos e por meio dos discursos materializados em alguma forma linguageira, os quais circulam no meio social. No nosso caso, o discurso materializa-se em fotografias, que podem ter tanto caráter jornalístico quanto documental.

A abordagem de Moscovici (2011) compreende as representações sociais como mecanismos e estruturas que nos ajudam a nos familiarizarmos com determinadas visões de mundo, espécies de modelos recorrentes e reconhecíveis, para, então, entendermos e

julgarmos as coisas e pessoas desse mundo. O autor exemplifica: "Quando classificamos uma pessoa entre os neuróticos, os judeus ou os pobres, nós obviamente não estamos apenas colocando um fato, mas avaliando-o e rotulando-o" (MOSCOVICI, 2011, p. 62).

São as representações sociais, constituídas por crenças, conhecimentos e opiniões partilhados, que nos possibilitam interpretar a realidade por meio de simbolizações e significações, integrando nossa vida cotidiana, sustentadas por discursos, sejam estes verbais, visuais, gestuais etc., ou seja, pela linguagem. Desse modo, as representações organizam-se em esquemas para classificar e julgar o mundo e o homem, isto é, em 
sistemas de pensamento que produzem os imaginários sociodiscursivos, os quais constituem uma proposição de visão de mundo, materializadas discursivamente.

Um desses discursos é o jornalístico. Portanto, é importante compreendermos como essas representações são mobilizadas discursivamente no e pelo jornalismo e para quais imaginários são capazes de nos direcionar. Afinal, não podemos perder de vista que todo discurso é intencional, carrega um projeto de fala. Como explica a Teoria Semiolinguística, o ato de linguagem ou de comunicação é fundado na intenção e realizado como projeto de influência (CHARAUDEAU, 2005). Ademais, a fotografia, enquanto discurso, propõe um modo de olhar para determinado recorte da realidade, a partir do enquadramento escolhido, que vai sugerir uma leitura possível. Quando olhamos para uma foto de uma favela ou de moradores desse local, acessamos representações que temos sobre eles, o que significa classificá-los a partir de um conjunto de regras ou comportamentos prévios que conhecemos. Esse processo de categorização tende à generalização, porque nos leva a escolher um modelo estocado em nossa memória, estabelecendo uma relação que pode ser positiva ou negativa (MOSCOVICI, 2011).

Ao estudarmos o processo de criação, manutenção e reforço de representações sobre as favelas e seus residentes ao longo do tempo, percebemos que algumas representações negativas se encontram cristalizadas, pela perpetuação de um discurso predominantemente ligado à pobreza e à violência ${ }^{5}$. Esclarecemos que optamos por empregar o termo representações sociais cristalizadas em vez de estereótipos, a partir de reflexões de Amossy (2006). A autora define o estereótipo como representação ou imagem coletiva simplificada e cristalizada de seres e coisas, modelos que fazem a mediação entre nós e o real. Nós já herdaríamos culturalmente algumas dessas imagens e construiríamos outras ao longo de nossa vida, e elas influenciariam nossas atitudes e nossos comportamentos. Assim, o processo de estereotipagem tornaria o singular em uma categoria geral com atributos mais ou menos fixos, criando uma espécie de esquema coletivo estável, o qual ajudaria a nortear nossos julgamentos. Por exemplo, se falamos

\footnotetext{
${ }^{5}$ Cf. Barcelos, 2016.
} 
em "favelado", qual imagem você acessa? Como você vê a pessoa que se "encaixa" nessa categoria?

Geralmente, quando se fala em estereótipo, pensa-se em uma característica generalizadora de cunho negativo. No entanto, como mencionamos, quando acessamos algum estereótipo, podemos estabelecer uma relação positiva ou negativa com ele. Por serem representações socialmente partilhadas, eles são importantes nas ações comunicativas e no convívio social, e sua estabilidade é relativa ao grupo que partilha dele, ou seja, ele é tributário de modelos culturais. Por isso, podemos não entender, por exemplo, uma piada contada em outro país, pois acessamos diferentes representações sociais em diferentes contextos culturais.

Amossy \& Herschberg-Pierrot (2011) nos mostram que o estereótipo começa a carregar um aspecto pejorativo, principalmente após os anos 1950, devido a estudos que o encaravam como processo de categorização e generalização que simplifica e distancia o real, favorecendo uma visão esquemática e deformada do outro que geraria preconceitos. As autoras explicam o caráter ambivalente da noção, que pode ser compreendida tanto como modelos preexistentes que ajudam a compreender o mundo e nortear as condutas, quanto como imagens coletivas fixas de caráter redutor e nocivo. Por essa razão, optamos pelo emprego da expressão representações sociais cristalizadas para aquelas mais fixas, que categorizam com mais rigidez, independentemente de terem caráter negativo ou positivo, pois esse aspecto dependerá de seu uso, do discurso que as engendra, em qual situação, com qual intenção, a partir de qual conteúdo, voltado para qual interlocutor.

Numa perspectiva que se interessa pelo imaginário social, à lógica das representações coletivas através das quais um grupo percebe e interpreta o mundo, o termo representação social tem sem dúvida vantagem sobre o de estereótipo por não ser carregado de conotações negativas. (AMOSSY \& HERSCHBERG-PIERROT, 2011, p. 53)

Portanto, na análise das fotos, podemos verificar quais representações sociais podem ser acessadas e quais imaginários sociodiscursivos elas engendrariam. 


\section{O jornal "O Globo" e o programa Imagens do Povo}

Trabalhamos com dois grupos de imagens: um primeiro, de fotos publicadas no jornal "O Globo", e um segundo, com fotos do livro "Imagens do Povo". Neste tópico, situaremos cada uma dessas instâncias produtoras do discurso.

O jornal diário "O Globo" existe desde 1925 e pertence às Organizações Globo, de propriedade da família Marinho. Direcionado às classes A e B da Região Metropolitana do Rio de Janeiro, o veículo ocupa o primeiro lugar entre os jornais de referência de maior circulação no Brasil ${ }^{6}$, segundo a Associação Nacional de Jornais (ANJ).

Sua orientação política é considerada conservadora, se levarmos em conta que o veículo integra um conglomerado midiático caracterizado pelo monopólio familiar dos Marinho, apresenta pouca diversidade externa do ponto de vista político e, segundo estudos de Azevedo (2006, p.90), faz parte de uma imprensa que pratica "um jornalismo orientado prioritariamente para as elites". O próprio jornal não apresenta seu posicionamento político-ideológico, insistindo no paradigma da imparcialidade. $\mathrm{O}$ item B do tópico 4, seção II, dos seus Princípios Editoriais, afirma que a opinião do Grupo vem expressa nos editoriais e que reflete a visão de seu conselho editorial, composto por membros da família Marinho. Nos editoriais, é possível identificar posicionamentos como defesa do livre mercado, moralismo na vida pública e manutenção de instituições sociais tradicionais, por exemplo ${ }^{7}$.

Selecionamos todas as imagens que mostram cenas em favelas da cidade com a presença de pessoas, publicadas, de domingo a segunda-feira, durante o período de nosso recorte.

O livro "Imagens do Povo" é uma coletânea de fotografias sobre favelas do Rio de Janeiro, realizada por fotógrafos formados pela Escola de Fotógrafos Populares, do

\footnotetext{
${ }^{6}$ Dados de 2015 (os mais recentes publicados pela ANJ): circulação de cerca de 193 mil exemplares. De acordo com a Infoglobo, esse número é de cerca de 133 mil exemplares nos dias úteis e em torno de 180 mil aos domingos (Fonte: IVC, julho 2017).

${ }^{7}$ Ao verificarmos a trajetória histórica dos veículos da família Marinho, podemos identificar esse viés conservador, posicionado politicamente à direita, como o apoio à aliança conservadora nos anos 1950; a oposição às reformas de base propostas por João Goulart, com pensamento alinhado a grupos militares, setores conservadores da Igreja Católica, empresários, entre outros atores sociais; o contrato com a TimeLife, grupo norte-americano de linha retrógrada do Partido Republicano nos anos 1960; a resistência em cobrir as Diretas Já etc.
} 
programa Imagens do Povo. A obra, publicada pela editora Nau, do Rio de Janeiro, reúne 102 fotografias de 25 fotógrafos. Ele foi viabilizado por meio do edital de Artes Visuais, lançado em agosto de 2011, pela Secretaria de Estado de Cultura do Rio de Janeiro.

Criado pelo fotógrafo João Roberto Ripper, em 2004, como parte do programa sociopedagógico da organização não governamental Observatório de Favelas, o Imagens do Povo é um centro de documentação e formação de fotógrafos documentaristas. Os principais eixos do projeto são: a Escola de Fotógrafos Populares, a Agência Imagens do Povo e o seu acervo fotográfico. Seus objetivos vão além de iniciar jovens no ofício da fotografia e articular seu ingresso no mercado de trabalho. Os participantes, residentes de comunidades populares do Rio de Janeiro, Niterói e Baixada Fluminense, são estimulados a desenvolver uma concepção fotográfica crítica.

O foco está na formação de documentaristas fotográficos (potenciais multiplicadores do saber adquirido) capazes de desenvolver trabalhos autorais de registro de espaços populares, valorizando as histórias e as práticas culturais de suas comunidades, ampliando as possibilidades de difusão de novas imagens desses locais. Entre os objetivos do projeto está materializar uma fotografia engajada e solidária, capaz de denunciar as dificuldades das populações economicamente excluídas, sem deixar de destacar sua altivez, sensualidade e beleza, em oposição à visão estigmatizante com que a grande imprensa frequentemente trata o tema, associando as comunidades populares apenas ao tráfico e à violência ${ }^{8}$.

As imagens analisadas incluem fotos jornalísticas e/ou documentais. A delimitação desses dois campos é complexa, por apresentarem mais semelhanças que diferenças. Ambos possuem a intenção de informar e documentar a realidade, contam uma história em imagens e buscam o estudo da situação e dos sujeitos que dela fazem parte.

Para Sousa (2004, p.11), o fotojornalismo "pode abranger quer as fotografias de notícias, quer as fotografias dos grandes projetos documentais, passando pelas ilustrações fotográficas e pelos features". Para efeito didático, recorremos à diferenciação em relação à abordagem, feita pelo autor: enquanto o fotojornalista volta-se a assuntos "quentes" e

\footnotetext{
${ }^{8}$ Informações disponíveis na página do programa na internet: www.imagensdopovo.org.br.
} 
busca cumprir uma pauta, com ênfase na descrição/narração do acontecimento, o fotodocumentarista pode trabalhar com temas intemporais e com prazo mais dilatado, focando na forma como o acontecimento afeta as pessoas.

As fotos publicadas no jornal "O Globo" poderiam ser classificadas como jornalísticas, por cobrirem uma pauta em um tempo restrito pelas próprias características do veículo jornal diário; as fotos publicadas no livro "Imagens do Povo" possuiriam caráter mais documental, mas também podem ser utilizadas pela imprensa. Reiteramos que, se levarmos em consideração a abrangência do fotojornalismo, que também recorre a fotos documentais, em ambas as situações podemos falar de imagens fotojornalísticas.

Para analisar as imagens, recorremos às categorias tema, figuração de cena e imaginários sociodiscursivos, seguindo o seguinte percurso: observação do tema da foto a partir de dados paraimagéticos (pauta, legenda etc.); verificação do tema a partir da iconicidade, ou seja, do que sua superfície mostra; e, enfim, considerando as observações iniciais, buscamos identificar as representações sociais presentes, para perceber os imaginários evocados. Para chegar a essa proposição, passamos por diversos autores e suas abordagens, cada um colaborando a seu modo, como Barthes (1990), Aumont (1993), Gervereau (2004), Joly (2003), Kossoy (2007, 2009), Mendes (2010, 2013) e Charaudeau (2013). Também conduzimos nossas interpretações levando em conta as especificidades de cada instância produtora do discurso, inserida numa dada situação de comunicação, que rege a troca comunicativa.

\section{O que dizem as fotos de favelas cariocas}

$\mathrm{Na}$ análise das fotografias publicadas no jornal "O Globo", percebemos que a cobertura é bem pulverizada e não abarca o universo de mais de 750 favelas do Rio de Janeiro ${ }^{9}$, contemplando algumas comunidades das zonas Norte e Sul, sendo a Oeste praticamente invisibilizada. Porém, o tema tem alto grau de noticiabilidade, com média mensal de publicação de fotos em quase metade das edições.

\footnotetext{
${ }^{9}$ Segundo o IBGE, censo de 2010.
} 
Enquanto as favelas da zona Sul, majoritariamente aquelas que têm Unidades de Polícia Pacificadora (UPPs), são enquadradas a partir de imaginários de segurança, paz e tranquilidade, as da zona Norte aparecem como lugares de crime e perigo, com forte presença policial e arsenal militar. Entendemos que as representações de segurança na zona Sul estão alinhadas a um projeto de pacificação sustentado pela política pública das UPPs, enquanto a imagem da zona Norte permanece ancorada em imaginários de violência e criminalidade, o que poderia colaborar para justificar a mesma política, baseada em intervenção militar.

Os temas das imagens priorizaram pautas de tráfico de drogas (41\%) e UPPs (26\%), reforçando representações cristalizadas sobre as favelas. Embora a cobertura passe por temas diversos, a primazia de fotos que evidenciam operações militares e criminalidade fica evidente.

Já os moradores, presentes em $70 \%$ das fotos, aparecem de forma diversa em relação a idade e tipos físicos, a maioria situada em cenários que remetem ao que reconhecemos, em nossa memória visual, como a representação física da favela (morros, construções sem reboco, vielas), reduzindo o local a tais características. Imageticamente, não encontramos nada que pudesse estigmatizá-los enquanto indivíduos. No entanto, quando aparecem como protagonistas, geralmente são como testemunhas da paz do lugar após a UPP, ou em cenas de cordialidade com policiais militares. Como a maior parte das fotos inclui a presença militar, identificamos que os moradores são representados como vítimas do tráfico que necessitam de auxílio. O eixo da pobreza e da precariedade está presente, mas de modo pontual, não configurando imaginários predominantes, fugindo do estigma da miséria. Percebemos que:

A representação social de favela como lugar do perigo e que necessita de
intervenção, por se configurar um problema, permaneceria desde os primórdios
desses aglomerados, passando por outras representações que se diferenciam ao
longo do tempo, porém mantendo essa matriz com certa firmeza e estabilidade.
(...). As forças de segurança aparecem como aqueles que viriam para solucionar
a questão do tráfico e da criminalidade. Não temos acesso à complexidade que
envolve as relações entre a polícia do Rio de Janeiro e as populações dos
aglomerados. A tendência das imagens publicadas é para a simplificação e a
generalização dos assuntos abordados. Além disso, as imagens passam a
sensação de que a presença militar nas favelas cariocas é uma constante, o que
pode colaborar para naturalizar essa situação, ou seja, a intervenção militar
nesses lugares ser vista como comum, natural, um aspecto do cotidiano.
(BARCELOS, 2016, p. 318-319) 
Já a abordagem do livro "Imagens do Povo" é completamente diferente daquela do jornal "O Globo". A maior parte das imagens mostra o cotidiano das favelas (31\%), cenas de lazer infantil (20\%) e cultura e lazer (10\% cada). Os outros temas englobam carnaval, jovens, esporte, projetos sociais, trabalho e religiosidade. Há apenas uma foto de operação policial, mas com foco em um morador que foge com uma criança no colo em uma rua urbanizada, que poderia ser qualquer rua da cidade. A maioria das imagens retrata crianças e adolescentes (30\%) e adultos (21\%). As outras trazem grupos mistos (16\%) e o restante não identifica os personagens. Assim como no jornal "O Globo", as favelas abordadas não são representativas do total de aglomerados do Rio, ficando focados principalmente na Maré (41\%), sede do programa Imagens do Povo e da Escola de Fotógrafos Populares, no Complexo do Alemão (20\%) e no Jacarezinho (12\%), todas situadas na zona Norte. Porém, ao contrário do que mostra "O Globo", não são cenários de violência, ou que envolvam aspectos negativos, mas sim cenas que mostram momentos de descontração, lazer e vida cotidiana tranquila, porém sem complexidades. $\mathrm{O}$ enquadramento temático é positivo: as pessoas arrumam suas casas, andam pelas ruas, trabalham; as crianças brincam na rua, pulam corda, jogam futebol, nadam, chupam picolé, soltam pipa.

Percebemos que, assim como "O Globo" generaliza pelo viés da violência, em dicotomia com a pacificação, mostrando segurança x criminalidade, o "Imagens do Povo" também generaliza, porém pelo viés da alegria cotidiana, buscando engendrar um imaginário de vida tranquila, de despreocupação que, sabemos, não condiz com a realidade das comunidades populares do Rio de Janeiro, que enfrentam vários problemas na luta por seus direitos. Ao buscar fugir do que consideram uma imagem estigmatizada das favelas, os fotógrafos populares também reduzem a diversidade e a complexidade desses locais. Acreditamos que eles colaboram com a visibilidade desses aspectos ao fotografá-los e fazerem essas representações sociais positivas circularem, de modo a se contraporem ao discurso que cristaliza aspectos negativos centrados no tráfico e na violência. No entanto, eles não chegam, a partir das fotos publicadas no livro, a demonstrarem uma concepção fotográfica crítica, conforme proposta do programa. Cremos que as fotos do livro cumprem o objetivo de registrar os espaços populares, 
valorizando suas histórias e práticas culturais. Parece-nos que se trata de uma fotografia solidária, como desejam, mas ainda não poderia ser configurada como engajada no caso dessas imagens específicas, pois não denuncia as dificuldades do que eles chamam de populações economicamente excluídas.

\section{Algumas considerações}

Ao verificarmos como as imagens fotojornalísticas carregam sentidos a partir de determinadas propostas discursivas, compreendemos sua relevância na construção de subjetividades. Uma vez que os discursos são intencionais, ou seja, procuram promover uma troca comunicativa a partir de estratégias para obter os sentidos desejados, é fundamental refletirmos sobre a responsabilidade da produção e circulação dessas fotografias, pois seu discurso, ao circular socialmente, pode colaborar para reforçar representações sociais cristalizadas, sejam elas de cunho positivo ou negativo e, no caso de uma visão que estigmatiza atores sociais e seus espaços de sociabilidade, podem gerar preconceitos.

No caso das imagens analisadas, verificamos as diferentes intenções de duas instâncias produtoras distintas e como essa intencionalidade repercute no discurso fotográfico, conduzindo a imaginários sociodiscursivos em direções quase que opostas. Enquanto o jornal "O Globo" insiste em manter e reforçar representações sustentadas por visões de mundo que reduzem as favelas à criminalidade e violência, à necessidade de pacificação, as fotos do livro "Imagens do Povo" buscam mostrar um cenário positivo da vida comunitária, a partir de cenas cotidianas centradas principalmente no lazer, com destaque para imagens de criança, capazes de acessar imaginários da infância feliz, em cenas que não englobam a realidade desses locais em sua complexidade.

Assim, ambas as propostas seguem no sentido da generalização, ainda que a partir de diferentes intenções. Tal percepção nos leva a refletir sobre quais seriam os caminhos possíveis de representação fotojornalística das favelas e de seus moradores em fotos que sejam capazes de ampliar o espectro, de mostrar a complexidade desses atores e espaços, fugindo do estigma, da redução, da generalização, porém que consigam acessar representações partilhadas, fundamentais para que a troca comunicativa se efetive. Trata- 
se de um desafio e também de uma proposta técnica, ética e estética, que poderia ser encampada por acadêmicos e profissionais, tanto em reflexões teóricas quanto na prática cotidiana.

Torna-se relevante levar tais discussões para as salas de aula e os encontros de professores e profissionais a fim de que, ao pensar sobre o fazer (foto) jornalístico, seja possível a construção de soluções conjuntas. Não há respostas certeiras para o desafio de que o fotojornalismo seja inclusivo, diverso e revelador de complexidades, porém há um possível direcionador do olhar, que propomos aqui: a dignidade humana. Se consideramos que aquele recorte feito a partir do click é capaz de preservar a dignidade do ser humano, se ele não é coisificado, se ele se mantém pleno de seus direitos humanos, respeitados ao ser retratado, já é um começo. Um bom começo.

\section{Referências}

AMOSSY, Ruth. L'argumentation dans le discours. $2^{\text {a }}$ ed. Paris: Armand Colin, 2009.

AMOSSY, Ruth; HERSCHBERG-PIERROT, Anne. Stéréotypes et clichés. Langue, discours, société. $3^{\mathrm{a}}$ éd. Paris: Armand Colin, 2011.

AZEVEDO, Fernando Antônio. Mídia e democracia no Brasil: relações entre o sistema de mídia e o sistema político. Opinião Pública, Campinas, v. 12, n. 1, p. 88-113, abril/maio, 2006. Disponível em: <http://www.scielo.br/pdf/op/v12n1/29399.pdf>. Acesso em: 12 dez. 2017.

AUMONT, Jacques. A imagem. $2^{\text {a }}$ ed. Campinas, SP: Papirus, 1993.

BARCELOS, Janaina Dias. Imagem e produção de sentido sobre favelas cariocas em fotos jornalísticas. 2016. $341 \mathrm{f}$. Tese (Doutorado em Estudos Linguísticos) - Faculdade de Letras, Universidade Federal de Minas Gerais, Belo Horizonte, 2016.

BARTHES, Roland. A escritura do visível. In: O óbvio e o obtuso. Rio de Janeiro: Nova Fronteira, 1990, p. 10-43.

CAMPOS, Andrelino. Do quilombo à favela. A produção do "espaço criminalizado" no Rio de Janeiro. 2. ed. Rio de Janeiro: Bertrand Brasil, 2007.

CHARAUDEAU, Patrick. Imagem, mídia e política: construção, efeitos de sentido, dramatização, ética. In: MENDES, Emília (Coord.) et al. (Orgs.). Imagem e discurso. Belo Horizonte: FALE/UFMG, 2013, p. 383-405.

CHARAUDEAU, Patrick. Les stéréotypes, c'est bien, les imaginaries, c'est mieux. In: BOYER, Henri. Stéréotypage, stéréotypes: fonctionnements ordinnaires et mises en scène. Langue (s), discours, Paris: Harmattan, v. 4, 2007, p. 49-63.

CHARAUDEAU, Patrick. Uma análise semiolinguística do texto e do discurso. In: PAULIUKONIS, M. A. L.; GRAVASSI, S. (Orgs.). Da língua ao discurso: reflexões para o ensino. Rio de Janeiro: Lucena, 2005, p. 11-27.

FAUSTINI, Marcus. Fim do "boom" da periferia. O Globo, Rio de Janeiro, 29 dez. 2015, Cultura. n. p.

FREITAS, Ricardo Ferreira et al. Em nome do espetáculo: megaeventos, cidades e representações midiáticas. In: IV CONGRESSO BRASILEIRO CIENTÍFICO DE COMUNICAÇÃO ORGANIZACIONAL E DE RELAÇÕES PÚBLICAS, 2010, Porto Alegre. [Anais eletrônicos]. 
Porto

Alegre,

Abrarcorp,

2010.

Disponível

em:

$<$ http://www.abrapcorp.org.br/anais2010/GT6/GT6_Freitas_etal.pdf >. Acesso em: 20 set. 2017.

GERVEREAU, Laurent. Voir, comprendre, analyser les images. $4^{\mathrm{a}}$. éd. Paris: Éditions La Découverte, 2004.

JOLY, Martine. La interpretación de la imagen: entre memoria, estereotipo y sedución. Barcelona: Paidós Comunicación, 2003.

KOSSOY, Boris. Realidades e ficções na trama fotográfica. 4a . ed. São Paulo: Ateliê Editorial, 2009.

KOSSOY, Boris. Os tempos da fotografia. O efêmero e o perpétuo. Cotia, SP: Ateliê Editorial, 2007.

LOPES, Adriana Carvalho. A favela tem nome próprio: a (re) significação do local na linguagem do funk carioca. Revista Brasileira de Linguística Aplicada - $R B L A$, Belo Horizonte, v. 9, n. 2, p. 369-390, 2009. Disponível em: <http://www.scielo.br/pdf/rbla/v9n2/02.pdf >. Acesso em: 20 set. 2017.

MATHEUS, Letícia Cantarela; SILVA, Pedro Henrique. Território retomado: o noticiário sobre operações militares em favelas no Rio de Janeiro. Revista Ecopós, v. 16, n. 3, p. 44-60, setembro/dezembro 2013.2 Disponível em: $<$ https://revistas.ufrj.br/index.php/eco_pos/article/view/831>. Acesso em: 19 set. 2017.

MENDES, Emília. Análise do discurso e iconicidade: uma proposta teórico-metodológica. In: MENDES, Emília (coord.) et al. (orgs.). Imagem e discurso. Belo Horizonte: FALE/UFMG, 2013, p. 125-156.

MENDES, Emília. Publicidade e imagem: uma proposta de estudo. In: FÓRUM INTERNACIONAL DE ANÁLISE DO DISCURSO, 2, 2010, Rio de Janeiro. Anais. Homenagem a Patrick Charaudeau. Rio de Janeiro: UFRJ, 2010, p. 91-101.

MOSCOVICI, Serge. Representações sociais. Investigações em psicologia social. $8^{\mathrm{a}}$. ed. Petrópolis, Rio de Janeiro: Vozes, 2011.

OBSERVATÓRIO DE FAVELAS. O que é favela, afinal? Coletânea de textos. In: SOUZA E SILVA, Jailson de (org.). O que é favela, afinal? Rio de Janeiro: Observatório de Favelas, 2009, p. 21-23.

RIPPER, João Roberto, GASTALDONI, Dante, MAZZA, Joana (Orgs.). Imagens do povo. Rio de Janeiro: Nau, 2012.

ROCHA, Daniella Guedes. Da Batalha à Guerra do Rio: uma abordagem espaço-temporal da representação das favelas na imprensa carioca. XVII ENCONTRO NACIONAL DE ESTUDOS POPULACIONAIS, 2010, Caxambu (MG). Anais. Disponível em: $<$ http://portalpbh.pbh.gov.br/pbh/ecp/files.do?evento=download\&urlArqPlc=da_batalh_a_guerr a_no_rj_represen_imprens_favelas.pdf $>$. Acesso em: 18 set. 2017.

SILVA, Jailson de Souza e; BARBOSA, Jorge Luiz. Favela. Alegria e dor na cidade. Rio de Janeiro: Editora Senac Rio, 2005.

SOUSA, Jorge Pedro. Fotojornalismo. Introdução à história, às técnicas e à linguagem da fotografia na imprensa. Florianópolis: Letras Contemporâneas, 2004.

VALLADARES, Licia do Prado. A invenção da favela. Do mito de origem a favela.com. Rio de Janeiro: Editora FGV, 2005.

VALLADARES, Licia. A gênese da favela carioca. A produção anterior às ciências sociais. Revista Brasileira de Ciências Sociais, Rio de Janeiro, v. 15, n. 44, p. 5-34, outubro 2000. Disponível em: <http://www.scielo.br/pdf/rbcsoc/v15n44/4145>. Acesso em: 19 set. 2017.

ZALUAR, Alba; ALVITO, Marcos (Orgs.). Um século de favela. $2^{a}$. ed. Rio de Janeiro: Editora FGV, 1999. 